\title{
Home Availability and the Impact of Weekly Stressful Events Are Associated with Fruit and Vegetable Intake among African American and Hispanic/Latina Women
}

\author{
Tracey A. Ledoux, Scherezade K. Mama, Daniel P. O'Connor, Heather Adamus, \\ Margaret L. Fraser, and Rebecca E. Lee \\ Department of Health and Human Performance, Texas Obesity Research Center, University of Houston, \\ 3855 Holman Street Garrison Room 104, Houston, TX 77204-6015, USA \\ Correspondence should be addressed to Tracey A. Ledoux, taledoux@uh.edu
}

Received 29 August 2011; Revised 16 January 2012; Accepted 28 February 2012

Academic Editor: Sandra G. Affenito

Copyright (C) 2012 Tracey A. Ledoux et al. This is an open access article distributed under the Creative Commons Attribution License, which permits unrestricted use, distribution, and reproduction in any medium, provided the original work is properly cited.

Background. Mediating and moderating variables may interfere with the association between neighborhood availability of grocery stores (NAG) and supermarkets (NAS) and fruit and vegetable (FV) intake. Objective. The purpose of this study was to test mediation of home availability of FV (HAFV) and moderation of impact of weekly stressful events (IWSE) on the association between NAG and NAS with FV consumption among African American (AA) and Hispanic/Latina (HL) women. Methods. Three hundred nine AA and HL, 25-60 year old women in the Health Is Power (HIP) randomized controlled trial completed validated measures of HAFV, IWSE, and FV intake at baseline. Trained field assessors coded NAG and NAS. Institutional Review Board approval was obtained. Results. NAG and NAS were not associated with FV intake or HAFV, so HAFV was not a mediator. HAFV (std. Beta $=.29, P<0.001)$ and IWSE (std. Beta $=.17 ; P<0.05)$ were related to FV intake $\left(R^{2}=0.17 ; P<0.001\right)$, but IWSE was not a moderator. Conclusion. Increasing HAFV and decreasing the IWSE should increase FV consumption. The extent to which the neighborhood environment is related to the home food environment and diet, and the mechanisms for the association between IWSE and diet should be examined in future research.

\section{Introduction}

Adequate consumption of fruits and vegetables may reduce risks for cardiovascular disease [1], obesity [2], and diabetes [3] among adults. African American and Hispanic/Latino adults present with higher rates of heart disease [4], obesity [5], and diabetes [6] compared with their white peers. Data from the National Health and Nutrition Examination Survey showed the majority of African American [7] and Hispanic/ Latino [8] adults failed to meet United States Department of Agriculture Dietary Guidelines for dietary intake of fruits and vegetables and had lower intake of fruits and vegetables compared with their white peers [9]. Increasing fruit and vegetable consumption among African American and Hispanic/Latino adults may reduce disparities in related health outcomes.
Ecologic models posit that health behaviors such as fruit and vegetable consumption are influenced by individual, sociocultural, organizational, community and policy level factors [10-13]. Low-income Hispanic/Latino and African American neighborhoods have fewer stores that sell fruits and vegetables compared with higher income or white neighborhoods [14-21]. However, neighborhood availability of food stores has been associated with diet quality only in some studies [15, 22-27]; not all [28-35]. This suggests that the association between neighborhood availability of food stores and diet is complicated by other variables, which may be potential targets for tailored interventions aimed at increasing fruit and vegetable consumption among underrepresented groups [36]. It is possible that unidentified mediators and moderators of the association between neighborhood availability of food stores and diet have 
compromised the ability to detect a relationship between the two consistently.

The association between neighborhood food store availability and fruit and vegetable intake may differ depending on food store type. Supermarkets are large self-service food markets of household foods and nonedible goods [15, 37]. Grocery stores are small "mom and pop" stores that sell a limited number of household foods and nonedible goods $[15,37]$. Supermarkets offer a larger variety of healthy, highquality fruits and vegetables at lower cost compared with smaller neighborhood grocery stores [24, 38]. Women who shop at supermarkets eat more fruits and vegetables compared with those who shop at grocery stores [24] suggesting neighborhood availability of supermarkets has a stronger influence on fruit and vegetable consumption compared with neighborhood availability of grocery stores. Unfortunately, low-income predominantly Hispanic or Latino and African American neighborhoods typically have fewer supermarkets compared with grocery stores $[16,25,39]$ suggesting the quality of stores available in low-income predominantly Hispanic or Latino and African American neighborhoods may contribute to poor dietary habits and low intake of fruits and vegetables.

Home availability of fruits and vegetables may mediate the relationship between neighborhood availability of grocery stores and supermarkets and fruit and vegetable intake. No known studies have examined the relationship between neighborhood availability of grocery stores and supermarkets and home availability of fruits and vegetables, but it is assumed that food purchases from supermarkets and grocery stores are primarily for the home. The relationship between home availability of fruits and vegetables and dietary intake of fruits and vegetables has been shown among adults $[40,41]$. In addition there is an association between food purchases from supermarkets and dietary intake [4245]. No known studies have tested whether home availability of fruits and vegetables mediates the association between neighborhood availability of grocery stores and supermarkets and fruit and vegetable intake.

Food shopping and meal preparation require substantial time, attention, and planning. Qualitative and quantitative studies have shown that higher fruit and vegetable consumption is associated with greater time and effort spent in food purchasing and meal preparation [46-50]. Perceived stress has been inversely related to diet quality [47, 51, 52], perhaps because the time and attention needed to cope or deal with stressful events overrides time and attention needed for healthy food shopping and meal preparation. It is possible the impact of weekly stressful events moderates the associations between neighborhood grocery store and supermarket availability, home availability of fruits and vegetables, and fruit and vegetable intake.

The purpose of this study was to determine whether home availability of fruits and vegetables mediates the association between neighborhood availability of grocery stores or supermarkets and fruit and vegetable intake; whether the impact of weekly stressful events moderates the associations between (1) neighborhood availability of grocery stores or supermarkets and home availability of fruits and vegetables

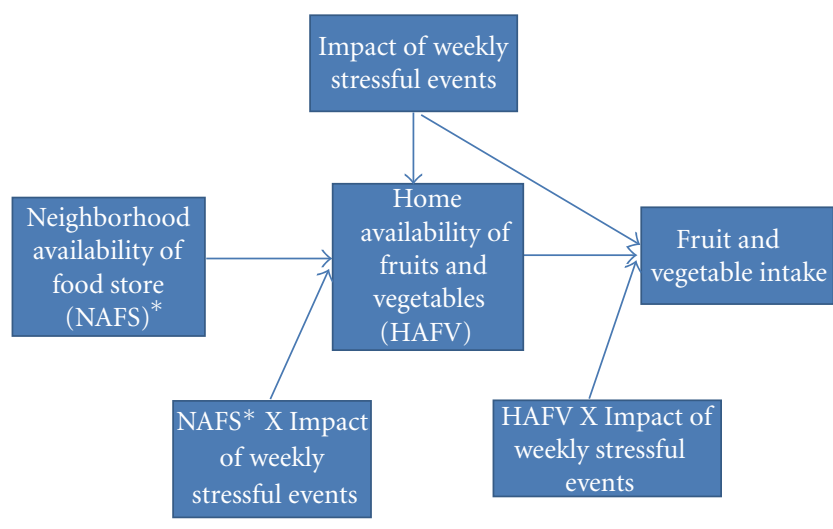

* Food store refers to either supermarket or grocery store in this study.

FIgURE 1: Conceptual model of the association between neighborhood availability of food stores and fruit and vegetable intake.

and (2) home availability of fruits and vegetables and dietary intake of fruits and vegetables (see Figure 1). The moderating effect of the impact of weekly stressful events would be most relevant for household food shoppers and meal preparers. Women are the primary food shoppers and meal preparers in most households particularly among African American and Hispanic or Latino families [53]; therefore, only women were examined in this study.

\section{Method}

2.1. Design and Sample. A descriptive cross-sectional study was conducted using baseline data from a larger randomized controlled trial, Health Is Power (HIP) [53]. The purpose of HIP was to test a transcultural, community-based intervention to increase physical activity and improve dietary habits among African American and Hispanic or Latina women from Houston and Austin, TX [53-55]. Four hundred ten apparently healthy African American and Hispanic or Latina women (311 in Houston and 99 in Austin) participated in HIP. In Houston, 84.6\% identified as African American and $15.4 \%$ identified as Hispanic or Latina; all subjects in Austin identified as Hispanic or Latina. The study sample and design have been described previously $[53,54]$.

\subsection{Individual Measures}

Demographics. Women completed interviewer-administered questionnaires and a physical assessment at the baseline (T1) health assessment. The Maternal and Infant Health Assessment (MIHA) was used to measure subjects' education, parents' education, and income. The MIHA is modeled on the Centers for Disease Control and Prevention's Pregnancy Risk Assessment Monitoring System (PRAMS)and is considered valid for African American and Hispanic or Latina women of all income statuses [56].

Fruit and Vegetable Intake. Consumption of fruits and vegetables, the dependent variable (see Figure 1), was measured 
using the National Cancer Institute's Fruit and Vegetable Screener $[57,58]$. Respondents reported fruit and vegetable consumption in terms of frequency and amount consumed over the last month. The Fruit and Vegetable Screener has adequate validity ( $r=0.68$ in men, 0.49 in women) in white adults when compared with the By-Meal Screener [57], and similar validity in ethnic women from underrepresented groups when compared with the National Cancer Institute's Diet History Questionnaire reported servings of fruits $(r=0.52)$ and vegetables $(r=0.23)$. Raw, frozen, canned, and juice varieties of fruits and vegetables are included in the screener [54], and scores reflect average number of servings of fruits and vegetables consumed per day. Scores may be as low as zero without upper limit.

Weekly Stress Inventory (WSI). The impact of weekly stressful events was hypothesized to moderate the association between neighborhood availability of supermarkets and grocery stores and home availability of fruits and vegetables and also the association between home availability of fruits and vegetables and fruit and vegetable consumption (see Figure 1). The WSI is a self-report questionnaire of the number of stressful events within the past week (WSI-event) [59] and the perceived impact of those events (WSI-impact). The WSI-impact scale scores were used in this study only. For the WSI-Impact, respondents indicate how stressful each of 87 stressful events of the last week were on a Likerttype scale ( 1 = "happened but not stressful"; 7 = "extremely stressful") [59]. Scores on the WSI-impact can range from 0 to 696 with high scores indicating multiple stressful events that were perceived as very stressful. In a standardization sample, the internal consistency proved excellent for the WSI-impact with coefficients ranging from 0.93 to 0.97 , with no difference by sex or race [59]. Internal consistency for this sample was 0.92 , which is very good. The WSI has been validated and used among ethnically and socioeconomically diverse samples $[59,60]$.

Home Availability of Fruits and Vegetables. Questionnaire requires respondents to indicate from a list of 32 foods, which foods and the version of the food (fresh, canned, or frozen) they had in the home in the last month [61]. Scores may range from 0 to 32. This instrument has demonstrated good internal consistency (Cronbach's alpha $=0.77$ ) and moderate test-retest correlation (ICC $r=0.50$ ) [61]. For the purpose of this study, a sum score for total home availability of fruits and vegetables was used in analyses, with higher scores indicating greater abundance of fruits and vegetables available in the home in the last month. Fruit juice was included in the category of fruit, but potato salad, coleslaw, and French fries were excluded. Home availability of fruits and vegetables was hypothesized to mediate the relationship between neighborhood availability of supermarkets and grocery stores and fruit and vegetable intake (see Figure 1).

\subsection{Environmental Measures}

The Goods and Services Inventory (GASI). Instrument [62] was used by trained personnel to measure 19 types of goods and services within a defined area. This study used only neighborhood availability of grocery stores and supermarkets, which were the independent variables (see Figure 1), as these are the primary sources of fruits and vegetables purchased for the home [63]. The number of neighborhood grocery stores and supermarkets may be as low as zero without an upper limit.

\subsection{Procedure}

Individual Data Collection. Subjects were recruited via advertisements in local media and through posted announcements in bulletins of community partners to participate in a health promotion intervention aimed at increasing physical activity and/or fruit and vegetable consumption. Interested subjects completed a telephone-administered inclusionary screener, which included a brief description of the study and the Physical Activity Readiness Questionnaire (PARQ) [64]. Because the goal of the intervention was to increase physical activity, women who were already physically active were not eligible to participate. HIP inclusion criteria included healthy women (i.e., nonpregnant or lactating women without serious health complications) who were not physically active between the ages of 25 and 60 years old. HIP exclusion criteria included physically active women outside of the desired age range who were not willing or able to agree to study procedures (e.g., increase physical activity or change diet). The study protocol was approved by the University of Houston Committee for the Protection of Human Subjects before recruitment began. Women who met inclusion criteria gave written consent and completed a baseline (T1) health assessment. At the T1 assessment, subjects completed an interviewer administered questionnaire and anthropometric measures of BMI and body fat, and they were given a take home packet to complete prior to the next meeting (approximately one week later). The packet contained more detailed questionnaires not found in the interviewer-administered survey, including the WSI [65-67]. Baseline data from HIP subjects, who had complete data on all target variables of this study, were included in this study.

Environmental Data Collection. To complete environmental assessments, neighborhoods were first mapped using Geographical Information Systems (GISs) technology. Subjects' addresses were geocoded, and a subjects' neighborhoods were defined as the area within an 800 meter $(0.5$ mile) radius circumscribed around their home. An intersect command in ArcGIS was used to combine the neighborhood buffers and street centerlines to create a buffer streets layer. Field assessors completed an interactive training using standardized training PowerPoint slides with pictures and operational definitions over the course of a half day and completed at least four hours of field training. Environmental assessment procedures have been previously described in detail $[39,53$, $54,66,68-70]$.

Statistical Analyses. Data were screened for data entry errors or outliers before initiating data analysis. Preliminary data inspection assessed violation of the assumptions of 
TAble 1: Demographic characteristics of African American (AA) and Hispanic or Latina (HL) women of Health Is Power.

\begin{tabular}{|c|c|c|c|}
\hline & $\begin{array}{c}\mathrm{AA} \\
N=202 \\
\mathrm{M}, \mathrm{SD}\end{array}$ & $\begin{array}{c}\mathrm{HL} \\
N=107 \\
\mathrm{M}, \mathrm{SD}\end{array}$ & $\begin{array}{c}\text { Total } \\
N=309 \\
\mathrm{M}, \mathrm{SD}\end{array}$ \\
\hline \multicolumn{4}{|l|}{ Demographic variables } \\
\hline Age & $45.43,9.22$ & $46.44,10.09$ & $45.78,9.52$ \\
\hline BMI & $34.52,8.02$ & $33.49,8.29$ & $34.16,8.11$ \\
\hline \multicolumn{4}{|l|}{ Study variables } \\
\hline Neighborhood availability of supermarkets & $0.30,0.57$ & $0.27,0.54$ & $0.29,0.56$ \\
\hline Neighborhood availability of grocery stores & $0.84,1.25$ & $1.11,1.96$ & $1.01,1.66$ \\
\hline Impact of weekly stressful events & $79.97,64.24$ & $67.35,46.11$ & $76.47,59.91$ \\
\hline Home availability of FV & $20.91,6.23$ & $20.97,5.89$ & $20.93,6.10$ \\
\hline FV intake (average serving/day)* & $3.21,3.08$ & $2.44,2.03$ & $2.94,2.79$ \\
\hline
\end{tabular}

${ }^{*} P<0.05,{ }^{* *} P<0.01,{ }^{* * *} P<0.001$.

normality, linearity, multicollinearity, and homoscedasticity. Bivariate Pearson correlations and Chi square tests were conducted to determine if there were relationships or differences among or between the study variables and demographic variables. All analyses were adjusted for those demographic variables that were significantly correlated with study variables. Bivariate Pearson correlations among study variables among African American and Hispanic/Latina women separately showed that the study variables were related in similar patterns of significance (data not shown); therefore, it was decided to combine the sample to increase power to detect shared associations. All models were adjusted for race. The spread of WSI-impact scores was negatively and fruit and vegetable intake scores were positively skewed so they were $\log$ transformed prior to inclusion in analyses.

Mediators and Moderators Analyses. Please see Figure 1 for conceptual model of variables tested in this study. Mediators are variables that are part of the causal pathway between two related variables [71]. Moderators are variables that are not on the causal pathway between two related variables but influence their relationship [71]. For example, gender may be a moderator when an association between two variables exists among males but not females [71]. Variables that mediate an association between an independent variable and dependent variable are related to both the independent variable and dependent variable as part of the causal pathway [71]. Mediators explain some of the variance in the dependent variable; therefore, controlling for mediators changes the strength of the association between the independent variable and the dependent variable. To test for mediation, the association between two variables is tested with and without controlling for the hypothesized mediator. If the association is different depending on whether the mediator was controlled or not, mediation is determined. To test for moderating effects, the interactions between the hypothesized moderator and IV are tested, and, if significant, moderation effects are determined. Five linear regression analyses excluding cases pairwise were conducted. Model 1 tested the association between neighborhood availability of grocery stores, impact of weekly stressful events, and the interaction between neighborhood availability of grocery stores and impact of weekly stressful events with home availability of fruits and vegetables after adjusting for demographic variables. Model 2 tested the association between neighborhood availability of supermarkets, impact of weekly stressful events, and the interaction between neighborhood availability of supermarkets and impact of weekly stressful events with home availability of fruits and vegetables after adjusting for demographic variables. Model 3 tested the association of home availability of fruits and vegetables, impact of weekly stressful events, and the interaction between home availability of fruits and vegetables and impact of weekly stressful events with fruit and vegetable intake after adjusting for demographic variables. Model 4 tested the association between neighborhood availability of grocery stores and fruit and vegetable intake after adjusting for demographic variables. Model 5 tested the association between neighborhood availability of supermarkets and fruit and vegetable intake after adjusting for demographic variables. Standardized betas (std. Beta) were presented to assess the magnitude of the association between the independent and dependent variables. Analyses were performed using PASW18.0 (2010, Chicago, IL). The level of significance was set at $P<0.05$.

\section{Results}

Three hundred nine women from the HIP project provided complete data for this study. The full HIP sample has been described previously $[16,53,55,66,68-70]$, and Table 1 provides a brief description for this study. African American women reported greater fruit and vegetable intake compared with Hispanic or Latina women. Chi square test for independence showed African American women had significantly more education $(P=0.009)$ and income $(P<0.001)$ compared with Hispanic or Latina women in this sample (data not shown) $[54,55]$.

Table 2 shows correlations for the total sample among demographic and study variables. Neighborhood availability 
TABLE 2: Correlations among demographic, neighborhood availability of supermarkets and grocery stores, the impact of weekly stressful events, home availability of fruit and vegetable (FV), and FV intake among African American and Hispanic or Latino women from Health Is Power.

\begin{tabular}{|c|c|c|c|c|c|c|c|}
\hline & Age & BMI & NAS & NAG & $\begin{array}{l}\text { Impact of weekly } \\
\text { stressful events }\end{array}$ & HAFV & FV intake \\
\hline Age & 1 & & & & & & \\
\hline BMI & 0.10 & 1 & & & & & \\
\hline NAS & -0.08 & 0.04 & 1 & & & & \\
\hline NAG & 0.08 & $0.12^{*}$ & $0.16^{* *}$ & 1 & & & \\
\hline Impact of weekly stressful events & $-0.23^{* *}$ & -0.03 & -0.08 & $-0.18^{*}$ & 1 & & \\
\hline HAFV & 0.03 & -0.06 & 0.09 & 0.03 & -0.07 & 1 & \\
\hline FV Intake & 0.08 & -0.01 & 0.08 & -0.05 & $-0.19 *$ & $0.31^{* *}$ & 1 \\
\hline
\end{tabular}

NAS: neighborhood availability of supermarkets; NAG: neighborhood availability of grocery stores; HAFV: home availability of FV; ${ }^{*} P<0.05, * * P<0.01$, $* * * P<0.001$.

TABLE 3: Linear regression analyses of the association of home availability of fruit and vegetables and fruit and vegetable intake with neighborhood availability of grocery stores and supermarkets, impact of weekly stressful events, home availability of fruit and vegetables, and interaction effects after controlling for demographic variables among African American and Hispanic or Latino women from Health Is Power ${ }^{\dagger}$.

\begin{tabular}{|c|c|c|c|c|c|}
\hline Model & Independent variables & Std. Beta & Dependent variables & Model $^{\dagger} R^{2}$ & $P$ \\
\hline & NAG & 0.11 & & & \\
\hline \multirow[t]{3}{*}{1} & Impact of weekly stressful events & -0.08 & HAFV & 0.03 & 0.81 \\
\hline & NAG X impact of weekly stressful events & 0.15 & & & \\
\hline & NAS & 0.10 & & & \\
\hline \multirow[t]{3}{*}{2} & Impact of weekly stressful events & -0.06 & HAFV & 0.02 & 0.90 \\
\hline & NAS X impact of weekly stressful events & 0.01 & & & \\
\hline & HAFV & $0.29 * * *$ & & & \\
\hline \multirow[t]{2}{*}{3} & Impact of weekly stressful events & $-0.17^{*}$ & FV intake & 0.17 & $<0.001$ \\
\hline & HAFV X impact of weekly stressful events & 0.05 & & & \\
\hline 4 & NAG & -0.03 & FV Intake & 0.05 & 0.02 \\
\hline 5 & NAS & 0.10 & FV Intake & 0.06 & 0.007 \\
\hline
\end{tabular}

NAS: neighborhood availability of supermarkets; NAG: neighborhood availability of grocery stores; HAFV: home availability of $\mathrm{FV} ;{ }^{*} P<0.05, * * * P<0.001$.

${ }^{\dagger}$ All models adjusted for age, BMI, race, education, and income.

of grocery stores and supermarkets was significantly positively related. The impact of weekly stressful events was negatively related to grocery stores and fruit and vegetable intake. Fruit and vegetable intake and home availability of fruits and vegetables were significantly positively related. Age was significantly negatively related to impact of weekly stressful events; BMI was significantly negatively related to neighborhood availability of grocery stores. Group differences on each of the study variables across income and education groups showed that there were no differences across education groups (less than high school education, high school, some college, and college graduate) on fruit and vegetable intake, home availability of fruits and vegetables, impact of weekly stressful events, neighborhood availability of grocery stores, or supermarkets. There were no differences across income groups $(<100 \%, 101-200 \%, 201-300 \%, 301-$ $400 \%$, and $401 \%$ + federal poverty level) on home availability of fruits and vegetables, impact of weekly stressful events, neighborhood availability of grocery stores, or supermarkets, but there were significant differences on fruit and vegetable intake $(F(4,278)=3.84, P=0.002)$ with those earning 201$300 \%$ federal poverty level (FPL) consuming significantly less fruits and vegetables compared with those in the $401 \%+$ FPL category (mean difference 0.47, $P=0.002$ ). Given the differences on some study variables by race and income and significant associations between demographic and study variables, all linear regression models tested were adjusted for these potential confounding variables (i.e., race, income, BMI, age).

See Table 3 for linear regression results of all models. Linear regression analyses showed neither the association of neighborhood availability of grocery stores (Model 1) nor neighborhood availability of supermarkets (Model 2) with home availability of fruits and vegetables was significant, after adjusting for potential confounding demographic variables. The association of home availability of fruits and vegetables on fruit and vegetable intake was significant, after controlling for potential confounding variables (Model 3). Home availability of fruits and vegetables (std. Beta $=0.29$, $P<0.001)$ and impact of weekly stressful events (std. 
Beta $=-0.17, P<0.05)$ were unique predictors in this model, but the interaction between home availability of fruits and vegetables and the impact of weekly stressful events was not significant $(P>0.05)$; therefore, the impact of weekly stressful events was not a moderator. Neither neighborhood availability of grocery stores (Model 4) nor neighborhood availability of supermarkets (Model 5) was unique predictors of fruit and vegetable intake after adjusting for demographic variables indicating home availability of fruits and vegetables was not a mediator of neighborhood availability of either food environment variable and fruit and vegetable intake.

\section{Discussion}

Among African American and Hispanic or Latina women, home availability of fruits and vegetables was positively and impact of weekly stressful events was inversely related to fruit and vegetable intake, but the impact of weekly stressful events did not influence the degree to which home availability of fruits and vegetables was related to fruit and vegetable intake (i.e., impact of weekly stressful events was not a moderator). Other studies have shown that home availability of fruits and vegetables was related to fruit and vegetable consumption among adults [40, 41, 45]. In one study, those who were of the opinion that "there was not much fruit in my household" were less likely to consume fruit daily, and those who believed "the person who cooks in my household does not cook many vegetables" were less likely to consume vegetables daily [45]. Others have shown subject self-report on inventories of home availability of fruits and vegetables was related to dietary intake of fruits and vegetables $[40,41]$. Based on results of this study, those of others, and theory, changes to the home food environment should promote changes in the diets of household members. In one study, African American and Hispanic/Latina households had fewer essential nutrients compared with foods available in white households [72], demonstrating the need for interventions to improve the health quality of foods available in African American and Hispanic/Latina households. While there have been some pilot studies showing interventions aimed at changing the home food environment are feasible and acceptable [73, 74], there have been no known large randomized controlled trials to test effectiveness of such interventions.

The impact of weekly stressful events was not related to home availability of fruits and vegetables, but it was inversely related to fruit and vegetable consumption. The mechanism for the association between the impact of weekly stressful events and fruit and vegetable consumption is not known but several explanations seem plausible. The average American makes over 220 decisions regarding food acquisition, preparation, service, consumption, and storage per day [63]. The Food Choice Process Model posits distal life course events and experiences, the present social and personal context, and proximal personal food thoughts and values have a reciprocal relationship with food behaviors [75] indicating that urgent and emergent stressors of high impact may interfere with food decisions at each level of this model. Research has shown that demands on time from work [76], family [77, 78], or both [46] have been related to unhealthy eating habits like eating out or skipping meals. Mothers and fathers reported coping with work and family stress by reducing time and effort for meals, reducing expectations for food and eating, and compromising food and eating for other family needs [77]. Moreover, a body of qualitative research reported women in low-wage, insecure, inflexible jobs with children perceived unexpected events, noncontributing partners, and minimal control over their environment to be barriers to healthy food purchasing and preparation [79]. Future research should examine the extent to which the impact of weekly stressful events competes with time and attention for food behaviors.

A second possible explanation for the inverse association between the impact of weekly stressful events and fruit and vegetable consumption is that chronic stress may trigger emotional overeating $[51,76,77,80]$. Theories of overeating suggest some obese individuals, overeat in response to negative emotions, but normal weight individuals who are not preoccupied with their weight, dieting, or food actually eat less in response to negative affect $[78,79,81]$. Foods consumed during emotional overeating are usually energy dense [82]; therefore, diets of emotional overeaters may lack fruits and vegetables. More research is needed to understand the mechanisms for the association between chronic stress and fruit and vegetable intake, so that interventions to promote fruit and vegetable consumption can target stress in the most effective manner.

Neighborhood availability of neither grocery stores nor supermarkets was related to either home availability of fruits and vegetables or fruit and vegetable intake, so home availability of fruits and vegetables was not a mediator of fruit and vegetable intake. Results were consistent with a number of other studies that failed to show an association between neighborhood availability of fruits and vegetables and fruits and vegetables consumption [29-35] but were inconsistent with studies that did find this association [22-27] and with ecologic models, which posit environmental factors influence behaviors $[12,13]$. Two recent systematic reviews concluded the association between the neighborhood food environment and dietary intake was weak and inconsistent [31, 32]. This area of research has been criticized for reliance on less rigorous study designs (e.g., cross sectional studies) and limitations in measurement of diet (i.e., under- and overreporting are significant problems with several measures of diet, particularly food frequency questionnaires [83]) and the food environment [84]. In this study, it was hypothesized that mediation effects of home availability of fruits and vegetables and moderation effects of impact of weekly stressful events would contribute to greater understanding of the food environment and fruit and vegetable consumption, but mediation and moderation effects were not found. Researchers should continue to identify mediators and moderators that may explain how the environment is related to dietary intake so that interventions and public policies have the desired impact.

A comparison of the methods used in this study with others that found an association between neighborhood availability of food stores and diet may highlight areas 
for future research. In this study, neighborhood was operationally defined as a 0.5 mile radius around subjects' residence, but fruits and vegetables purchased for the home may have come from stores outside of this boundary. In other studies among multiethnic adults, probability of having a healthy diet decreased as density of supermarkets within a 1 mile radius of home [23] or a census tract ( $>0.5$ mile from home) [25] decreased. Moreover, women in this sample may have purchased fruits and vegetables for the home from other types of food retail outlets compared with grocery stores or supermarkets, such as restaurants. In another study, across multiple ethnic groups, takeout restaurants were a popular source of fruits and vegetables purchased for the home [63], and, in another study, adults who perceived fruits and vegetables as available in restaurants reported greater self-efficacy for consuming fruits and vegetables compared with those who did not perceive fruits and vegetables to be available in restaurants [28]. Last, two very large recent studies (one longitudinal and one cross-sectional) provided evidence to suggest that neighborhood food store availability may be a stronger determinant of fast food consumption compared with fruit and vegetable consumption $[29,30]$. Future research should examine a greater range of food retail outlet types, other components of the diet besides fruits and vegetables (e.g., fast food), and larger radius around the home to determine how the neighborhood food environment relates to the home food environment and diet.

Strengths of this study include a large diverse sample, objective measurement of neighborhood food stores, and control of potential confounding demographic variables in analyses. However, use of self-report measures (subject to bias) and the fruit and vegetable screener (less valid and reliable compared with more intensive measures of diet such as 24 hour dietary recalls) may be considered limitations. Healthy African American and Hispanic or Latina women, who do not engage in physical activity regularly, were recruited for this study; therefore, results are generalizable only to women who meet these criteria.

\section{Conclusion}

African American and Hispanic or Latina women do not generally meet dietary guidelines for fruit and vegetable consumption putting them at risk for related chronic diseases like diabetes and heart disease. Ecologic models posit environmental factors contribute to individual behaviors like diet. Results showed home availability of fruits and vegetables and impact of weekly stressful events were unique and significant determinants of fruit and vegetable intake. Neighborhood availability of grocery stores and supermarkets was not related to home availability of fruits and vegetables or fruit and vegetable intake, and impact of weekly stressful events was not a moderator for any associations. Future interventions should target the home environment and impact of weekly stressful events to promote increased fruit and vegetable consumption. Future research should measure a broader range of neighborhood environment and dietary variables with greater precision and rigor to determine the extent to which and how the neighborhood environment is related to the home food environment and diet. Last, the mechanisms for the association between impact of weekly stressful events and diet should be further explored.

\section{Acknowledgments}

The Health Is Power (HIP) project was supported by a grant from the National Institutes of Health, National Cancer Institute (1R01CA109403) award to R. E. Lee at the University of Houston. The authors would like to thank the many students and trainees of the Understanding Neighborhood Determinants of Obesity (UNDO) research team who helped to collect, enter, and process data.

\section{References}

[1] K. J. Joshipura, H. C. Hung, T. Y. Li et al., "Intakes of fruits, vegetables and carbohydrate and the risk of CVD," Public Health Nutrition, vol. 12, no. 1, pp. 115-121, 2009.

[2] T. A. Ledoux, M. D. Hingle, and T. Baranowski, "Relationship of fruit and vegetable intake with adiposity: a systematic review," Obesity Reviews, vol. 12, no. 501, pp. e143-e150, 2011.

[3] E. Erber, B. N. Hopping, A. Grandinetti, S. Y. Park, L. N. Kolonel, and G. Maskarinec, "Dietary patterns and risk for diabetes: the multiethnic cohort," Diabetes Care, vol. 33, no. 3, pp. 532-538, 2010.

[4] A. M. Davis, L. M. Vinci, T. M. Okwuosa, A. R. Chase, and E. S. Huang, "Cardiovascular health disparities: a systematic review of health care interventions," Medical Care Research and Review, vol. 64, no. 5, supplement, pp. 29S-100S, 2007.

[5] K. M. Flegal, M. D. Carroll, C. L. Ogden, and L. R. Curtin, "Prevalence and trends in obesity among US adults, 19992008," JAMA-Journal of the American Medical Association, vol. 303, no. 3, pp. 235-241, 2010.

[6] M. E. Peek, A. Cargill, and E. S. Huang, "Diabetes health disparities: a systematic review of health care interventions," Medical Care Research and Review, vol. 64, no. 5, 2007.

[7] D. C. James, "Cluster analysis defines distinct dietary patterns for African-American men and women," Journal of the American Dietetic Association, vol. 109, no. 2, pp. 255-262, 2009.

[8] P. M. Carrera, X. Gao, and K. L. Tucker, "A study of dietary patterns in the Mexican-American population and their association with obesity," Journal of the American Dietetic Association, vol. 107, no. 10, pp. 1735-1742, 2007.

[9] S. S. Casagrande, Y. Wang, C. Anderson, and T. L. Gary, "Have Americans increased their fruit and vegetable intake? The trends between 1988 and 2002," American Journal of Preventive Medicine, vol. 32, no. 4, pp. 257-263, 2007.

[10] R. E. Lee, K. M. McAlexander, and J. A. Banda, Reversing the Obesogenic Environment, Human Kinetics, Champaign, Ill, USA, 2011.

[11] L. Frank, J. Kerr, B. Saelens, J. Sallis, K. Glanz, and J. Chapman, "Food outlet visits, physical activity and body weight: variations by gender and race-ethnicity," British Journal of Sports Medicine, vol. 43, no. 2, pp. 124-131, 2009.

[12] J. F. Sallis and K. Glanz, "Physical activity and food environments: solutions to the obesity epidemic," Milbank Quarterly, vol. 87, no. 1, pp. 123-154, 2009. 
[13] J. C. Spence and R. E. Lee, "Toward a comprehensive model of physical activity," Psychology of Sport and Exercise, vol. 4, no. 1, pp. 7-24, 2003.

[14] L. M. Powell, S. Slater, D. Mirtcheva, Y. Bao, and F. J. Chaloupka, "Food store availability and neighborhood characteristics in the United States," Preventive Medicine, vol. 44, no. 3, pp. 189-195, 2007.

[15] N. I. Larson, M. T. Story, and M. C. Nelson, "Neighborhood environments: disparities in access to healthy foods in the U.S.," American Journal of Preventive Medicine, vol. 36, no. 1, pp. 74-81, 2009.

[16] R. E. Lee, K. M. Heinrich, A. V. Medina et al., "A picture of the healthful food environment in two diverse urban cities," Journal of Environmental Health Insights, vol. 4, pp. 49-60, 2010.

[17] G. Regan, R. E. Lee, K. Booth, and J. Reese-Smith, "Obesogenic influences in public housing: a mixed-method analysis," American Journal of Health Promotion, vol. 20, no. 4, pp. 282-290, 2006.

[18] J. R. Sharkey and S. Horel, "Neighborhood socioeconomic deprivation and minority composition are associated with better potential spatial access to the ground-truthed food environment in a large rural area," Journal of Nutrition, vol. 138, no. 3, pp. 620-627, 2008.

[19] J. Beaulac, E. Kristjansson, and S. Cummins, "A systematic review of food deserts, 1966-2007," Preventing Chronic Disease, vol. 6, no. 3, article A105, 2009.

[20] R. E. Walker, C. R. Keane, and J. G. Burke, "Disparities and access to healthy food in the United States: a review of food deserts literature," Health and Place, vol. 16, no. 5, pp. 876884,2010

[21] D. S. Grigsby-Toussaint, S. N. Zenk, A. Odoms-Young, L. Ruggiero, and I. Moise, "Availability of commonly consumed and culturally specific fruits and vegetables in African-american and Latino neighborhoods," Journal of the American Dietetic Association, vol. 110, no. 5, pp. 746-752, 2010.

[22] A. Michimi and M. C. Wimberly, "Associations of supermarket accessibility with obesity and fruit and vegetable consumption in the conterminous United States," International Journal of Health Geographics, vol. 9, article 49, 2010.

[23] L. V. Moore, A. V. Diez Roux, J. A. Nettleton, and D. R. Jacobs Jr., "Associations of the local food environment with diet quality-a comparison of assessments based on surveys and geographic information systems: the multi-ethnic study of atherosclerosis," American Journal of Epidemiology, vol. 167, no. 8, pp. 917-924, 2008.

[24] S. N. Zenk, A. J. Schulz, T. Hollis-Neely et al., "Fruit and vegetable intake in African Americans: income and store characteristics," American Journal of Preventive Medicine, vol. 29, no. 1, pp. 1-9, 2005.

[25] K. Morland, S. Wing, and A. D. Roux, "The contextual effect of the local food environment on residents' diets: the atherosclerosis risk in communities study," American Journal of Public Health, vol. 92, no. 11, pp. 1761-1767, 2002.

[26] N. Wrigley, D. Warm, B. Margetts, and A. Whelan, "Assessing the impact of improved retail access on diet in a "food desert": a preliminary report," Urban Studies, vol. 39, no. 11, pp. 20612082, 2002.

[27] V. Inglis, K. Ball, and D. Crawford, "Socioeconomic variations in women's diets: what is the role of perceptions of the local food environment?" Journal of Epidemiology and Community Health, vol. 62, no. 3, pp. 191-197, 2008.

[28] T. O. Erinosho, A. Y. Oh, R. P. Moser, L. C. Nebeling, K. L. Davis, and A. L. Yaroch, "Association between perceived food environment and self-efficacy for fruit and vegetable consumption among US adults, 2007," Preventing Chronic Disease, vol. 9, article E10, 2012.

[29] J. Boone-Heinonen, P. Gordon-Larsen, C. I. Kiefe, J. M. Shikany, C. E. Lewis, and B. M. Popkin, "Fast food restaurants and food stores-longitudinal associations with diet in young to middle-aged adults: the CARDIA study," Archives of Internal Medicine, vol. 171, no. 13, pp. 1162-1170, 2011.

[30] S. C. Lucan and N. Mitra, "Perceptions of the food environment are associated with fast-food (not fruit-and-vegetable) consumption: findings from multi-level models," International Journal of Public Health. In press.

[31] K. Giskes, M. Avendaňo, J. Brug, and A. E. Kunst, "A systematic review of studies on socioeconomic inequalities in dietary intakes associated with weight gain and overweight/obesity conducted among European adults," Obesity Reviews, vol. 11, no. 6, pp. 413-429, 2010.

[32] K. Giskes, F. van Lenthe, M. Avendano-Pabon, and J. Brug, "A systematic review of environmental factors and obesogenic dietary intakes among adults: are we getting closer to understanding obesogenic environments?" Obesity Reviews, vol. 12, no. 501, pp. e95-e106, 2011.

[33] K. Ball, D. Crawford, and G. Mishra, "Socio-economic inequalities in women's fruit and vegetable intakes: a multilevel study of individual, social and environmental mediators," Public Health Nutrition, vol. 9, no. 5, pp. 623-630, 2006.

[34] J. N. Bodor, D. Rose, T. A. Farley, C. Swalm, and S. K. Scott, "Neighbourhood fruit and vegetable availability and consumption: the role of small food stores in an urban environment," Public Health Nutrition, vol. 11, no. 4, pp. 413-420, 2008.

[35] S. Cummins, M. Petticrew, C. Higgins, A. Findlay, and L. Sparks, "Large scale food retailing as an intervention for diet and health: quasi-experimental evaluation of a natural experiment," Journal of Epidemiology and Community Health, vol. 59, no. 12, pp. 1035-1040, 2005.

[36] T. Baranowski, E. Cerin, and J. Baranowski, "Steps in the design, development and formative evaluation of obesity prevention-related behavior change trials," International Journal of Behavioral Nutrition and Physical Activity, vol. 6, article 6, 2009.

[37] P. Kaufman, C. R. Handy, E. W. McLaughlin, K. Park, and G. M. Green, "Understanding the dynamics of produce markets: consumption and consolidation grow," Agricultre Information Bulletin no. 758, Food and Rural Economics Division, Economic Research Service, U.S. Department of Agriculture.

[38] K. M. Jetter and D. L. Cassady, "The availability and cost of healthier food alternatives," American Journal of Preventive Medicine, vol. 30, no. 1, pp. 38-44, 2006.

[39] Y. Kestens and M. Daniel, "Social inequalities in food exposure around schools in an urban area," American Journal of Preventive Medicine, vol. 39, no. 1, pp. 33-40, 2010.

[40] M. L. Gattshall, J. A. Shoup, J. A. Marshall, L. A. Crane, and P. A. Estabrooks, "Validation of a survey instrument to assess home environments for physical activity and healthy eating in overweight children," International Journal of Behavioral Nutrition and Physical Activity, vol. 5, article 3, 2008.

[41] J. A. Fulkerson, M. C. Nelson, L. Lytle, S. Moe, C. Heitzler, and K. E. Pasch, "The validation of a home food inventory," International Journal of Behavioral Nutrition and Physical Activity, vol. 5, article 55, 2008.

[42] H. Eyles, Y. Jiang, and C. Ni Mhurchu, "Use of household supermarket sales data to estimate nutrient intakes: a comparison with repeat 24-hour dietary recalls," Journal of the 
American Dietetic Association, vol. 110, no. 1, pp. 106-110, 2010.

[43] M. Nelson, P. A. Dyson, and A. A. Paul, "Family food purchases and home food consumption: comparison of nutrient contents," British Journal of Nutrition, vol. 54, no. 2, pp. 373$387,1985$.

[44] J. K. Ransley, J. K. Donnelly, T. N. Khara et al., "The use of supermarket till receipts to determine the fat and energy intake in a UK population," Public Health Nutrition, vol. 4, no. 6, pp. 1279-1286, 2001.

[45] K. Giskes, F. J. Van Lenthe, C. B. M. Kamphuis, M. Huisman, J. Brug, and J. P. Mackenbach, "Household and food shopping environments: do they play a role in socioeconomic inequalities in fruit and vegetable consumption? A multilevel study among Dutch adults," Journal of Epidemiology and Community Health, vol. 63, no. 2, pp. 113-120, 2009.

[46] M. Beshara, A. Hutchinson, and C. Wilson, "Preparing meals under time stress. The experience of working mothers," Appetite, vol. 55, no. 3, pp. 695-700, 2010.

[47] R. Sims, S. Gordon, W. Garcia et al., "Perceived stress and eating behaviors in a community-based sample of African Americans," Eating Behaviors, vol. 9, no. 2, pp. 137-142, 2008.

[48] D. Crawford, K. Ball, G. Mishra, J. Salmon, and A. Timperio, "Which food-related behaviours are associated with healthier intakes of fruits and vegetables among women?" Public Health Nutrition, vol. 10, no. 3, pp. 256-265, 2007.

[49] K. Wiig and C. Smith, "The art of grocery shopping on a food stamp budget: factors influencing the food choices of lowincome women as they try to make ends meet," Public Health Nutrition, vol. 12, no. 10, pp. 1726-1734, 2009.

[50] E. Winkler and G. Turrell, "Confidence to cook vegetables and the buying habits of Australian households," Journal of the American Dietetic Association, vol. 110, no. 5, pp. S52-S61, 2010.

[51] S. J. Torres and C. A. Nowson, "Relationship between stress, eating behavior, and obesity," Nutrition, vol. 23, no. 11-12, pp. 887-894, 2007.

[52] S. P. Wamala, A. Wolk, and K. Orth-Gomér, "Determinants of obesity in relation to socioeconomic status among middleaged Swedish women," Preventive Medicine, vol. 26, no. 5 I, pp. 734-744, 1997.

[53] R. E. Lee, A. V. Medina, S. K. Mama et al., "Health is power: an ecological, theory-based health intervention for women of color," Contemporary Clinical Trials, vol. 32, no. 6, pp. 916923, 2011.

[54] R. E. Lee, S. K. Mama, A. V. Medina et al., "Multiple measures of physical activity, dietary habits and weight status in African American and Hispanic or Latina women," Journal of Community Health, vol. 36, no. 6, pp. 1011-1023, 2011.

[55] R. E. Lee, D. P. O'Connor, R. Smith-Ray et al., "Mediating effects of group cohesion on physical activity and diet in women of color: Health Is Power," American Journal of Health Promotion, vol. 26, no. 4, pp. e116-e125, 2012.

[56] R. Sarnoff and D. Hughes, "Increasing health insurance coverage in the first year of life," Maternal and Child Health Journal, vol. 9, no. 4, pp. 343-350, 2005.

[57] F. E. Thompson, A. F. Subar, A. F. Smith et al., "Fruit and vegetable assessment: performance of 2 new short instruments and a food frequency questionnaire," Journal of the American Dietetic Association, vol. 102, no. 12, pp. 1764-1772, 2002.

[58] A. F. Subar, F. E. Thompson, V. Kipnis et al., "Comparative validation of the Block, Willett, and National Cancer Institute food frequency questionnaires: the eating at America's table study," American Journal of Epidemiology, vol. 154, no. 12, pp. 1089-1099, 2001.

[59] P. Brantley, G. Jones, and E. Boudreauz, "The weekly stress inventory," in Evaluating Stress: A Book of Resources, C. P. Zalaquett, Ed., Scarecrow Press, Landham, Mass, USA, 1997.

[60] I. C. Scarinci, S. C. Ames, and P. J. Brantley, "Chronic minor stressors and major life events experienced by low-income patients attending primary care clinics: a longitudinal examination," Journal of Behavioral Medicine, vol. 22, no. 2, pp. 143156, 1999.

[61] K. W. Cullen, L. M. Klesges, N. E. Sherwood et al., "Measurement characteristics of diet-related psychosocial questionnaires among African-American parents and their 8- to 10year-old daughters: results from the Girls' health Enrichment Multi-site Studies," Preventive Medicine, vol. 38, supplement, pp. S34-S42, 2004.

[62] H. Adamus, Y. Lopez, S. Das, and R. E. Lee, "A comprehensive analysis of objective measures of environmental support for physical activity and healthful eating," Annals of Behavioral Medicine. Under review.

[63] S. Yoo, T. Baranowski, M. Missaghian et al., "Food-purchasing patterns for home: a grocery store-intercept survey," Public Health Nutrition, vol. 9, no. 3, pp. 384-393, 2006.

[64] S. Thomas, J. Reading, and R. J. Shephard, "Revision of the physical activity readiness questionnaire (PAR-Q)," Canadian Journal of Sport Sciences, vol. 17, no. 4, pp. 338-345, 1992.

[65] C. S. Layne, S. K. Mama, J. A. Banda, and R. E. Lee, "Development of an ecologically valid approach to assess moderate physical activity using accelerometry in community dwelling women of color: a cross-sectional study," International Journal of Behavioral Nutrition and Physical Activity, vol. 8, article 21, 2011.

[66] K. M. McAlexander, S. K. Mama, A. Medina, D. P. O'Connor, and R. E. Lee, "The concordance of directly and indirectly measured built environment attributes and physical activity adoption," International Journal of Behavioral Nutrition and Physical Activity, vol. 8, article 72, 2011.

[67] S. K. Mama, B. E. Quill, M. E. Fernandez-Esquer, J. ReeseSmith, J. A. Banda, and R. E. Lee, "Body image and physical activity among African American and Hispanic or Latina women," Ethnicity \& Disease, vol. 21, no. 3, pp. 281-287, 2011.

[68] R. E. Lee, S. K. Mama, K. P. McAlexander, H. Adamus, and A. V. Medina, "Neighborhood and PA: neighborhood factors and physical activity in African American public housing residents." Journal of Physical Activity \& Health, vol. 8, supplement 1, pp. S83-S90, 2011.

[69] B. M. Parmenter, T. McMillan, C. Cubbin, and R. E. Lee, "Developing geospatial data management, recruitment, and analysis techniques for physical activity research," Journal of the Urban and Regional Information Systems Association, vol. 20, no. 2, pp. 13-19, 2008.

[70] R. E. Lee, K. M. Booth, J. Y. Reese-Smith, G. Regan, and H. H. Howard, "The Physical Activity Resource Assessment (PARA) instrument: evaluating features, amenities and incivilities of physical activity resources in urban neighborhoods," International Journal of Behavioral Nutrition and Physical Activity, vol. 2, article 13, 2005.

[71] R. M. Baron and D. A. Kenny, "The moderator-mediator variable distinction in social psychological research: conceptual, strategic, and statistical considerations," Journal of Personality and Social Psychology, vol. 51, no. 6, pp. 1173-1182, 1986.

[72] S. D. Schefske, A. C. Bellows, C. Byrd-Bredbenner et al., "Nutrient analysis of varying socioeconomic status home food 
environments in New Jersey," Appetite, vol. 54, no. 2, pp. 384389, 2010.

[73] J. A. Fulkerson, S. Rydell, and M. Y. Kubik, "Healthy Home Offerings via the Mealtime Environment (HOME): feasibility, acceptability, and outcomes of a pilot study," Obesity, vol. 18, supplement 1, pp. S69-S74, 2010.

[74] A. A. Gorin, H. A. Raynor, H. M. Niemeier, and R. R. Wing, "Home grocery delivery improves the household food environments of behavioral weight loss participants: results of an 8-week pilot study," International Journal of Behavioral Nutrition and Physical Activity, vol. 4, article 58, 2007.

[75] J. Sobal and C. A. Bisogni, "Constructing food choice decisions," Annals of Behavioral Medicine, vol. 38, supplement 1, pp. S37-S46, 2009.

[76] A. Peters and D. Langemann, "Stress and eating behavior," F1000 Biology Reports, vol. 2, no. 1, article 13, 2010.

[77] E. Epel, S. Jimenez, K. Brownell, L. Stroud, C. Stoney, and R. Niaura, "Are stress eaters at risk for the metabolic syndrome?" Annals of the New York Academy of Sciences, vol. 1032, pp. 208210, 2004.

[78] C. P. Herman and J. Polivy, Restrained Eating, Saunders, Philadelphia, Pa, USA, 1980.

[79] A. J. Stunkard and S. Messick, "The three-factor eating questionnaire to measure dietary restraint, disinhibition and hunger," Journal of Psychosomatic Research, vol. 29, no. 1, pp. 7183, 1985.

[80] T. Van Strien, J. E. R. Frijters, G. P. A. Bergers, and P. B. Defares, "The Dutch eating behavior questionnaire (DEBQ) for assessment of restrained, emotional, and external eating behavior," International Journal of Eating Disorders, vol. 5, no. 2, pp. 295-315, 1986.

[81] T. V. Van Strien, R. C. M. E. Engels, J. V. Leeuwe, and H. M. Snoek, "The Stice model of overeating: tests in clinical and non-clinical samples," Appetite, vol. 45, no. 3, pp. 205-213, 2005.

[82] C. H. Gilhooly, S. K. Das, J. K. Golden et al., "Food cravings and energy regulation: the characteristics of craved foods and their relationship with eating behaviors and weight change during 6 months of dietary energy restriction," International Journal of Obesity, vol. 31, no. 12, pp. 1849-1858, 2007.

[83] G. W. Greene, K. Resnicow, F. E. Thompson et al., "Correspondence of the NCI fruit and vegetable screener to repeat 24-H recalls and serum carotenoids in behavioral intervention trials," Journal of Nutrition, vol. 138, no. 1, pp. 200S-204S, 2008.

[84] L. A. Lytle, "Measuring the Food Environment. State of the Science," American Journal of Preventive Medicine, vol. 36, no. 4, supplement, pp. S134-S144, 2009. 


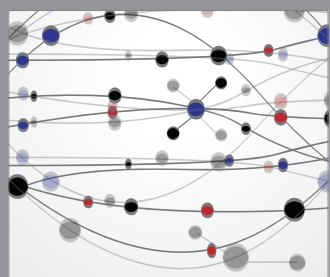

The Scientific World Journal
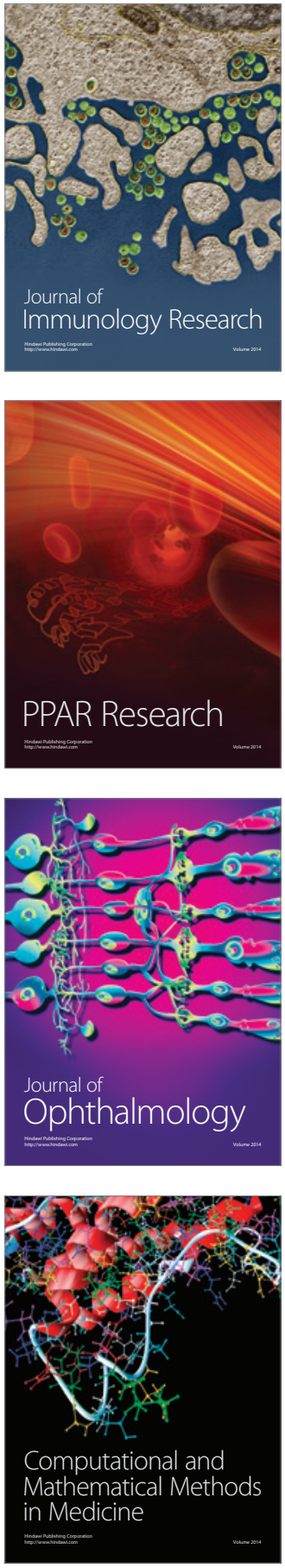

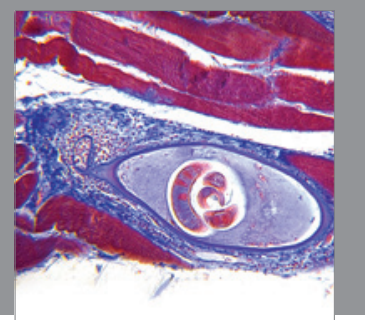

Gastroenterology

Research and Practice
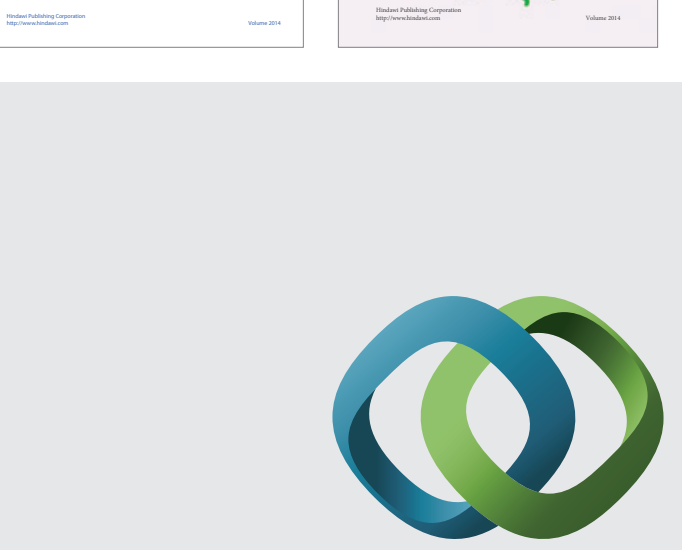

\section{Hindawi}

Submit your manuscripts at

http://www.hindawi.com
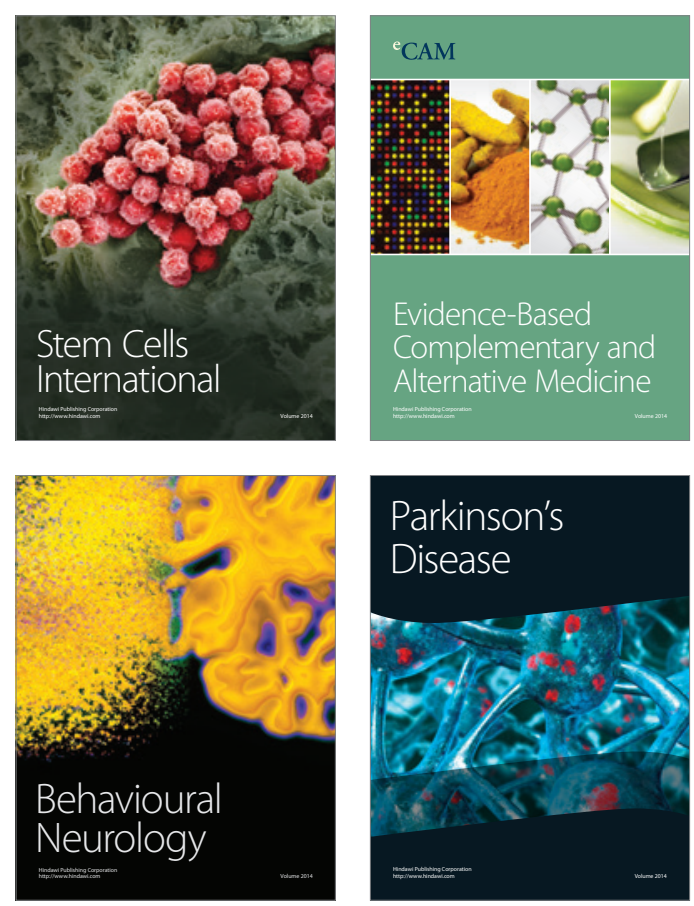

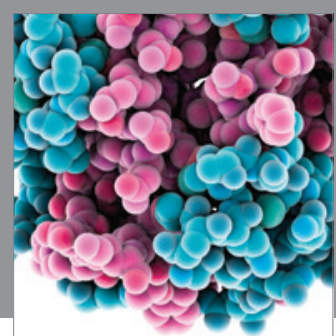

Journal of
Diabetes Research

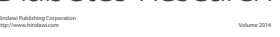

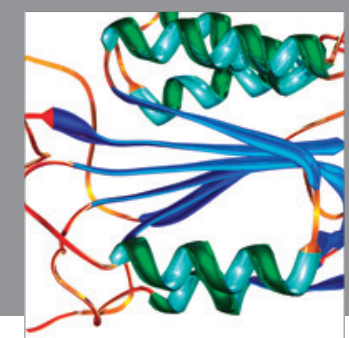

Disease Markers
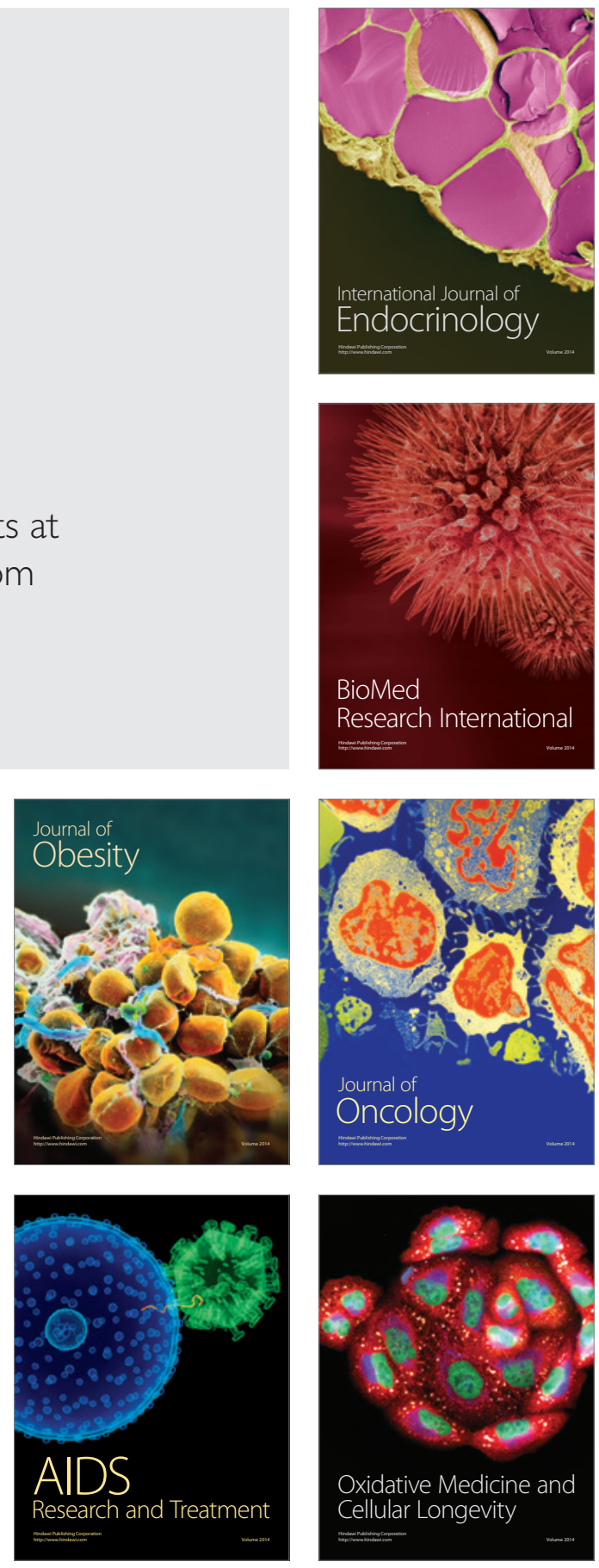